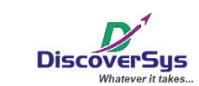

Published by DiscoverSys

\section{Risk Factors of Neonatal Sepsis at Perinatology Unit Sanglah General Public Hospital Denpasar}

\author{
Kurniasih Widayati, ${ }^{1,2 *}$ Desak Putu Yuli Kurniati, ${ }^{2,3}$ Gusti Ayu Trisna Windiani ${ }^{2}$
}

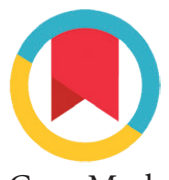

CrossMark

\section{ABSTRACT}

Background and purpose: Infant Mortality Rate (IMR) nationally in 2012 was 32 per 1000 live births and 29 per 1000 live births in Bali. This figure was higher than the target of the Millennium Development Goals (MDGs) in 2015 which amounted to 23 per 1000 live births. One of many factors that increase risk of infant mortality is neonatal sepsis. Research on neonatal sepsis has been done in Sanglah General Public Hospital but it was only a descriptive study. This study was conducted to determine the socio-demographic factors, clinical, environmental and invasive procedures associated with neonatal sepsis in the Sanglah General Public Hospital.

Methods: The study design was a case control with a sample of 30 cases and 30 controls that were selected randomly by matching on birth month of the register book of 1 January to 31 December 2014 at the Perinatology Unit Sanglah Hospital. The case groups were patients who were diagnosed with sepsis, and the control groups were not the sepsis. Data were collected from medical records of patients using extraction form. Bivariate analysis was conducted to determine crude OR and multivariate logistic regression method to determine adjusted $O R$.

Results: Bivariate analysis showed that factors that increase risk of neonatal sepsis were mothers who did not work or worked as laborers $(0 R=3.5 ; 95 \% \mathrm{Cl}: 1.1$ to 11.7), low birth weight ( $L B W)$ babies $(0 \mathrm{R}=6,6$; $95 \%$ Cl: 1.9 to 24.2$)$, infant care in an incubator ( $O R=4.1 ; 95 \%$ Cl: 1.2 to 14.3), infusion ( $O R=9.3 ; 95 \% \mathrm{Cl}: 1.7$ to 92.1$)$ and the administration of oxygen ( $\mathrm{OR}=7.0 ; 95 \% \mathrm{Cl}: 1.9$ to 29.7$)$. Multivariate analysis showed that the only variable significantly increases risk of sepsis was low birt weight ( $O R=20.2 ; 95 \%$ Cl: 1.4 to 289.7).

Conclusion: LBW was the risk factor of neonatal sepsis at Perinatology Unit, Sanglah General Public Hospital.

Keywords: risk factors, neonatal sepsis, Sanglah General Public Hospital

Cite This Article: Widayati, K., Kurniati, D.P.Y., Windiani, G.A.T. 2016. Risk Factors of Neonatal Sepsis at Perinatology Unit Sanglah General Public Hospital Denpasar. Public Health and Preventive Medicine Archive 4(1): 67-73. D01:10.15562/phpma.v4i1.59

\title{
Faktor Risiko Sepsis Neonatorum di Ruang Perinatologi Rumah Sakit Umum Pusat Sanglah Denpasar
}

${ }^{1}$ Nursing Academy of Kesdam IX/ Udayana Denpasar,

${ }^{2}$ Public Health Postgraduate Program Udayana University, ${ }^{3}$ chool of Public Health Udayana University

*Correspondence to: Kurniasih Widayati, Nursing Academy of Kesdam IX/ Udayana Denpasar, Public Health Postgraduate Program Udayana University

kurniasih_kesdam@yahoo.co.id dikumpulkan dari rekam medis pasien dengan formulir ekstraksi data. Analisis secara bivariat untuk mengetahui crude OR dan multivariat dengan metode regresi logistik untuk mengetahui adjusted OR.

Hasil: Analisis bivariat menunjukkan bahwa faktor yang meningkatkan risiko sepsis neonatorum adalah ibu yang tidak bekerja dan bekerja sebagai buruh dengan $0 \mathrm{R}=3,5(95 \% \mathrm{Cl}: 1,1-11,7)$, bayi berat lahir rendah (BBLR) dengan $\mathrm{OR}=6,6(95 \% \mathrm{Cl}: 1,9-24,2)$, perawatan bayi dalam inkubator dengan $0 \mathrm{R}=4,1(95 \% \mathrm{Cl}: 1,2-14,3)$, pemberian infus dengan $\mathrm{OR}=9,3(95 \% \mathrm{Cl}: 1,7-92,1)$ dan pemberian oksigen dengan $\mathrm{OR}=7,0$ (95\%Cl: 1,9-29,7). Analisis multivariat menunjukkan bahwa satu-satunya variabel yang bermakna meningkatkan risiko sepsis neonatorum adalah BBLR dengan OR=20,2 (95\%Cl: 1,4-289,7).

Simpulan: BBLR merupakan faktor risiko sepsis neonatorum di ruang perinatologi RSUP Sanglah Denpasar. 


\section{PENDAHULUAN}

Penurunan angka kematian bayi (AKB) merupakan salah satu target dari MDGs. ${ }^{1}$ Kejadian tertinggi di wilayah Afrika yaitu sebesar 60 per 1000 kelahiran hidup $(\mathrm{KH})$, lima kali lebih tinggi dari kawasan Eropa yaitu 11 per $1000 \mathrm{KH} .{ }^{2}$ Berdasarkan Survei Demografi dan Kesehatan Indonesia (SDKI) tahun 2012, angka kematian bayi secara nasional sebesar 32 per $1000 \mathrm{KH}$ dan di Provinsi Bali sebesar 29 per $1000 \mathrm{KH} .{ }^{3}$ Angka ini masih lebih tinggi dari target Millenium Development Goals (MDGs) tahun 2015 sebesar 23 per $1000 \mathrm{KH} .{ }^{5}$ Sebesar $42 \%$ kematian neonatus di negara berkembang disebabkan oleh infeksi termasuk sepsis neonatorum. ${ }^{6}$ Insiden sepsis neonatorum masih tinggi di negara berkembang yaitu 1,8-18 per $1000 \mathrm{KH}$. Insiden di rumah sakit rujukan di Indonesia 1,5\%-3,7\% dengan angka kematian sebesar 37,1\%-80\%. Insiden di Rumah Sakit Sanglah Denpasar pada tahun 2010 sebesar 5\% dengan tingkat kematian 30,4\%.,

Penelitian tentang faktor risiko sepsis neonatorum belum banyak dilakukan di Bali. Penelitian yang dilakukan oleh Junara pada tahun 2010 di Rumah Sakit Sanglah mendapatkan bahwa bayi berat lahir rendah (BBLR) dan lahir prematur berisiko 2,6 kali mengalami sepsis neonatorum. ${ }^{7}$ Namun penelitian tersebut tidak meneliti faktor risiko lainnya. Penelitian ini dilakukan untuk mengetahui faktor risiko sepsis neonatorum di Ruang Perinatologi RSUP Sanglah Denpasar yaitu faktor risiko BBLR, lahir prematur dan faktor risiko lainnya seperti sosiodemografi, klinis, lingkungan dan tindakan invasif.

\section{METODE}

Rancangan penelitian adalah kasus kontrol dengan jumlah sampel 30 kasus dan 30 kontrol yang dipilih secara acak dari buku register 1 Januari-31 Desember 2014 di ruang perinatologi RSUP Sanglah Denpasar dengan melakukan matching berdasarkan bulan kelahiran bayi. Kasus adalah pasien yang didiagnosa sepsis neonatorum dan kontrol adalah pasien bukan sepsis neonatorum. Data diambil dari rekam medis pasien dengan formulir ekstraksi data dari buku register di ruang perinatologi pasien pulang dengan melihat diagnosis ahkir pasien. Nomor rekam medik pasien dicocokkan di Bagian Rekam Medik dan apabila rekam medik tidak dijumpai maka pasien diganti dengan nomor berikutnya. Kasus dan kontrol dianggap tidak memenuhi syarat apabila ada kelainan kongenital pada pasien dan rekam medik pasien tidak tersedia. Data yang dikumpulkan adalah variabel sosiodemografi, klinis, lingkungan dan tindakan invasif. Variabel sosiodemografi terdiri dari umur ibu, pendidikan, pekerjaan, usia kehamilan dan jumlah kehamilan. Variabel pada bayi yaitu jenis kelamin bayi, berat badan lahir dan nilai apgar score. Variabel klinis terdiri dari mayor dan minor. Variabel klinis mayor yaitu suhu tubuh ibu, ketuban pecah dini dan fetal distress. Variabel klinis minor yaitu kondisi air ketuban, asfiksia, berat badan lahir, usia kehamilan, kelahiran kembar, ibu tersangka infeksi saluran kencing dan tersangka keputihan. Variabel tentang lingkungan adalah kelas perawatan, tempat persalinan, penolong dan cara persalinan serta status rujukan. Variabel tindakan invasif yaitu pemberian infus, pemeriksaan laboratorium, penggunaan inkubator, pemakaian oksigen dan penggunaan continous positive airway pressure (CPAP).

Dalam analisis data dilakukan pengelompokkan sebagai berikut: 1) jenis kelamin (laki-laki dan perempuan);2) pendidikan ibu (tinggi dan rendah); 3) pekerjaan ibu (PNS/swasta dan buruh/tidak bekerja); 4) faktor risiko mayor menjadi ya dan tidak; 5) faktor risiko minor dikategorikan ya dan tidak; 6) faktor tempat persalinan dikategorikan di rumah sakit dan diluar rumah sakit; 7) penolong persalinan dikategorikan dokter dan bidan praktek swasta; 8) rujukan dikategorikan dirujuk dan tidak dirujuk; 9) tindakan invasif dikategorikan ya bila dilakukan dan tidak bila tidak dilakukan.

Data dianalisis menggunakan program Stata SE 12.1. Analisis bivariat dilakukan untuk membandingkan kelompok kasus dan kontrol dan menghitung crude OR masing-masing faktor risiko. Analisis multivariat dilakukan dengan metode regresi logistik untuk mengetahui faktor risiko yang secara independen berhubungan dengan sepsis neonatorum dengan menghitung adjusted OR. ${ }^{8}$ Penelitian ini telah mendapat kelaikan etik dari Komisi Etik Penelitian Fakultas Kedokteran Universitas Udayana dan Rumah Sakit Sanglah Denpasar.

\section{HASIL}

Pada Tabel 1 dan 2 terlihat bahwa kelompok kasus dan kelompok kontrol sudah mirip $(p>0,05)$ pada semua variabel kecuali variabel pekerjaan ibu, BBLR, perawatan inkubator, pemasangan infus, pemberian oksigen $(p<0,05)$. Faktor risiko yang secara signifikan meningkatkan kejadian sepsis neonatorum adalah pekerjaan ibu dengan (crude $\mathrm{OR}=3,5 ; 95 \% \mathrm{CI}: 1,1-11,7)$, perawatan inkubator (crude $\mathrm{OR}=4,1 ; 95 \% \mathrm{CI}: 1,2-14,3$ ), pemasangan infus (crude OR=9,3; 95\%CI: 1,7-92,1), pemberian oksigen dengan (crude $\mathrm{OR}=7,0 ; 95 \% \mathrm{CI}$ : $1,9-29,7$ ) dan BBLR dengan (crude OR=6,6; 95\%CI: 1,9-24,2). Sedangkan pada tindakan pemeriksaan laboratorium tidak dapat dianalisis karena $100 \%$ pasien menjalani pemeriksaan laboratorium. 
Tabel 1 Crude odd ratio variabel sosiodemografis terhadap sepsis neonatorum

\begin{tabular}{|c|c|c|c|c|c|}
\hline \multirow[b]{2}{*}{ Faktor risiko } & \multicolumn{2}{|c|}{ Kelompok } & \multirow[b]{2}{*}{ Crude OR } & \multirow[b]{2}{*}{$95 \% \mathrm{Cl}$} & \multirow[b]{2}{*}{ Nilai p } \\
\hline & $\begin{array}{c}\text { Kontrol } \\
(n=30)\end{array}$ & $\begin{array}{c}\text { Kasus } \\
(n=30)\end{array}$ & & & \\
\hline \multicolumn{6}{|l|}{ Jenis kelamin bayi } \\
\hline Perempuan & $8(26,7)$ & $15(50,0)$ & 0,4 & $0,1-1,2$ & 0,063 \\
\hline Laki-laki & $22(73,3)$ & $15(50,0)$ & & & \\
\hline \multicolumn{6}{|l|}{ Pendidikan ibu } \\
\hline $\mathrm{SD}, \mathrm{SMP}$ & $12(40,0)$ & $11(36,7)$ & 1,2 & $0,4-3,7$ & 0,791 \\
\hline SMA, PT & $18(60,0)$ & $19(63,3)$ & & & \\
\hline \multicolumn{6}{|l|}{ Jenis pekerjaan ibu } \\
\hline PNS, swasta & $18(60,0)$ & $9(30,0)$ & 3,5 & $1,1-11,7$ & 0,020 \\
\hline Buruh, tidak bekerja & $12(40,0)$ & $21(70,0)$ & & & \\
\hline \multicolumn{6}{|l|}{ Kelas perawatan } \\
\hline Kelas VIP,I dan II & $7(23,3)$ & $5(16,7)$ & 1,5 & $0,4-7,0$ & 0,519 \\
\hline Kelas III & $23(76,7)$ & $25(83,3)$ & & & \\
\hline \multicolumn{6}{|l|}{ Cara persalinan } \\
\hline Spontan & $14(46,7)$ & $17(56,7)$ & 0,7 & $0,2-2,1$ & 0,438 \\
\hline SC/ forcep/ vakum & $16(53,3)$ & $13(43,3)$ & & & \\
\hline \multicolumn{6}{|l|}{ Tempat persalinan } \\
\hline Rumah sakit & $27(90,0)$ & $25(83,3)$ & 1,8 & $0,3-12,7$ & 0,448 \\
\hline Bidan praktik & $3(10,0)$ & $5(16,7)$ & & & \\
\hline \multicolumn{6}{|l|}{ Penolong persalinan } \\
\hline Dokter & $27(90,0)$ & $25(83,3)$ & 1,8 & $0,3-12,7$ & 0,448 \\
\hline Bidan & $3(10,0)$ & $5(16,7)$ & & & \\
\hline \multicolumn{6}{|l|}{ Rujukan } \\
\hline Tidak dirujuk & $18(60,0)$ & $13(43,3)$ & 2,0 & $0,6-6,2$ & 0,196 \\
\hline Dirujuk & $12(40,0)$ & $17(56,7)$ & & & \\
\hline \multicolumn{6}{|l|}{ Masuk inkubator } \\
\hline Tidak & $18(60,0)$ & $8(26,7)$ & 4,1 & $1,2-14,3$ & 0,009 \\
\hline Ya & $12(40.0)$ & $22(73,3)$ & & & \\
\hline \multicolumn{6}{|l|}{ Dipasang infus } \\
\hline Tidak & $12(40,0)$ & $2(6,7)$ & 9,3 & $1,7-92,1$ & 0,002 \\
\hline Ya & $18(60,0)$ & $28(93,3)$ & & & \\
\hline \multicolumn{6}{|l|}{ Diperiksa laboratorium } \\
\hline Tidak & $1(3,3)$ & $0(0,0)$ & - & - & 0,313 \\
\hline Ya & $29(96,7)$ & $30(100,0)$ & & & \\
\hline \multicolumn{6}{|l|}{ Diberi oksigen } \\
\hline Tidak & $17(58,6)$ & $5(16,7)$ & 7,0 & $1,9-29,7$ & 0,001 \\
\hline Ya & $12(41,4)$ & $25(83,3)$ & & & \\
\hline \multicolumn{6}{|l|}{ Dipasang CPAP } \\
\hline Tidak & $27(90.0)$ & $22(73,3)$ & 3,3 & $0,7-21,0$ & 0,095 \\
\hline Ya & $3(10,0)$ & $8(26,7)$ & & & \\
\hline
\end{tabular}

Pada analisis multivariat, variabel yang diikutkan dalam model adalah variabel yang mempunyai nilai $p>0,25$. Dalam analisis bivariat dijumpai
12 variabel yang sesuai kriteria dan dapat dimasukkan dalam analisis multivariat yaitu jenis kelamin bayi, pekerjaan ibu, usia kehamilan, bayi asfiksia, 
Tabel 2 Crude $O R$ variabel klinis terhadap risiko sepsis neonatorum

\begin{tabular}{|c|c|c|c|c|c|}
\hline \multirow[b]{2}{*}{ Faktor klinis } & \multicolumn{2}{|c|}{ Kelompok } & \multirow[b]{2}{*}{ Crude OR } & \multirow[b]{2}{*}{$95 \% \mathrm{Cl}$} & \multirow[b]{2}{*}{ Nilai $p$} \\
\hline & $\begin{array}{c}\text { Kontrol } \\
(n=30)\end{array}$ & $\begin{array}{l}\text { Kasus } \\
(n-30)\end{array}$ & & & \\
\hline \multicolumn{6}{|c|}{ Fakor klinis mayor } \\
\hline \multicolumn{6}{|c|}{ Ibu demam $>38^{\circ} \mathrm{C}$} \\
\hline Tidak & $28(93,3)$ & $29(96,7)$ & 0,5 & $0,0-9,9$ & 0,554 \\
\hline Ya & $2(6,7)$ & $1(3,3)$ & & & \\
\hline \multicolumn{6}{|l|}{ KPD $>24$ jam } \\
\hline Tidak & $29(96,7)$ & $27(90,0)$ & 3,2 & $0,2-174,9$ & 0,301 \\
\hline Ya & $1(3,3)$ & $3(10,0)$ & & & \\
\hline \multicolumn{6}{|l|}{ Fetal distress } \\
\hline Tidak & $28(93,3)$ & $26(86,7)$ & 2,1 & $0,3-25,4$ & 0,389 \\
\hline Ya & $2(6,7)$ & $4(13,3)$ & & & \\
\hline \multicolumn{6}{|l|}{ Ketuban hijau } \\
\hline Tidak & $25(83,3)$ & $26(86,7)$ & 0,8 & $0,1-4,1$ & 0,718 \\
\hline Ya & $5(16,7)$ & $4(13,3)$ & & & \\
\hline \multicolumn{6}{|c|}{ Faktor klinis minor } \\
\hline \multicolumn{6}{|l|}{$\mathrm{KPD}>12$ jam } \\
\hline Tidak & $29(96,7)$ & $28(93,3)$ & 2,1 & $0,1-126,3$ & 0,553 \\
\hline Ya & $1(3,3)$ & $2(6,7)$ & & & \\
\hline \multicolumn{6}{|l|}{ Asfiksia } \\
\hline Tidak & $18(60,0)$ & $12(40,0)$ & 2,3 & $0,7-7,2$ & 0,121 \\
\hline Ya & $12(40,0)$ & $18(60,0)$ & & & \\
\hline \multicolumn{6}{|l|}{ Berat badan lahir } \\
\hline BBLN & $23(76,7)$ & $10(33,3)$ & 6,6 & $1,9-24,2$ & 0,001 \\
\hline BBLR & $7(23,3)$ & $20(66,7)$ & & & \\
\hline \multicolumn{6}{|l|}{ Gemeli } \\
\hline Tidak & $28(93,3)$ & $27(90,0)$ & 1,6 & $0,2-19,8$ & 0,640 \\
\hline Ya & $2(6,7)$ & $3(10,0)$ & & & \\
\hline \multicolumn{6}{|l|}{ Keputihan } \\
\hline Tidak & $27(90,0)$ & $22(73,3)$ & 3,3 & $0,7-21,0$ & 0,095 \\
\hline Ya & $3(10,0)$ & $8(26,7)$ & & & \\
\hline \multicolumn{6}{|l|}{ Tersangka ISK } \\
\hline Tidak & $29(96,7)$ & $26(86,7)$ & 4,5 & $0,4-227,1$ & 0,161 \\
\hline Ya & $1(3,3)$ & $4(13,3)$ & & & \\
\hline \multicolumn{6}{|l|}{ Demam $>37^{\circ} \mathrm{C}$} \\
\hline Tidak & $29(96,7)$ & $29(96,7)$ & 1,0 & $0,0-81,2$ & 1,000 \\
\hline Ya & $1(3,3)$ & $1(3,3)$ & & & \\
\hline \multicolumn{6}{|l|}{ Usia kehamilan } \\
\hline Cukup bulan & $19(63,3)$ & $12(40,0)$ & 2,6 & $0,8-8,4$ & 0,071 \\
\hline Kurang bulan & $11(36,7)$ & $18(60,0)$ & & & \\
\hline \multicolumn{6}{|l|}{ Gravida } \\
\hline Primigravida & $12(40,0)$ & $11(36,7)$ & 1,2 & $0,4-3,7$ & 0,790 \\
\hline Multigravida & $18(60,0)$ & $19(63,3)$ & & & \\
\hline
\end{tabular}


Tabel 3 Adjusted OR faktor risiko sepsis neonatorum

\begin{tabular}{lcccc}
\hline & & \multicolumn{2}{c}{$\mathbf{9 5 \%} \mathbf{C l}$} & \\
\cline { 3 - 4 } Variabel & Adjusted OR & Lower & Upper & Nilai p \\
\hline Bayi laki-laki & 0,6 & 0,15 & 3,53 & 0,710 \\
Ibu bekerja tidak tetap & 2,0 & 0,41 & 9,89 & 0,394 \\
Kehamilan pretem & 0,1 & 0,03 & 2,98 & 0,177 \\
Bayi asfiksia & 0,4 & 0,10 & 2,53 & 0,328 \\
Bayi berat lahir rendah & 28,4 & 1,06 & 758,52 & $0,046^{*}$ \\
Ibu keputihan & 2,1 & 0,14 & 31,63 & 0,599 \\
Infeksi saluran kencing & 1,8 & 0,43 & 78,00 & 0,754 \\
Rujukan & 1,5 & 0,28 & 7,55 & 0,649 \\
Pemasangan infus & 17,4 & 1,45 & 208,26 & $0,024^{*}$ \\
Masuk inkubator & 2,6 & 0,33 & 20,72 & 0,364 \\
Pemasangan selang O2 & 0,7 & 0,60 & 22,77 & 0,161 \\
Pemasangan CPAP & 0,0 & 0,07 & 5,96 & 0,718 \\
\hline
\end{tabular}

BBLR, ibu tersangka keputihan, ibu tersangka infeksi saluran kemih, rujukan, bayi dipasang infus, bayi masuk inkubator, bayi menggunakan oksigen dan penggunaan CPAP. Variabel tersebut selanjutnya dianalisis dengan menggunakan regresi logistik metode enter yaitu secara bersama-sama memasukan semua variabel kedalam model.

Pada Tabel 3 disajikan hasil analisis multivariat dan dijumpai bahwa variabel yang secara signifikan meningkatkan risiko sepsis neonatorum ialah BBLR dengan adjusted OR=28,4 (95\%CI: 1,06$758,52)$ dan pemasangan infus dengan adjusted $\mathrm{OR}=17,4$ (95\%CI: 1,45-208,26), sedangkan variabel lainnya tidak dijumpai meningkatkan risiko terjadinya sepsis neonatorum.

\section{DISKUSI}

Pada penelitian ini dijumpai bahwa bayi berat lahir rendah secara bermakna meningkatkan risiko sepsis neonatorum. Hasil ini sejalan dengan penelitian Junara tahun (2012) tentang analisis insiden dan faktor risiko sepsis neonatorum yang mendapatkan bahwa BBLR juga meningkatkan risiko sepsis neonatorum di RSUP Sanglah Denpasar. ${ }^{7}$ Demikian juga dengan penelitian Leal (2012) menyatakan ada hubungan yang bermakna antara BBLR dengan sepsis neonatorum. ${ }^{9}$ Sedangkan penelitian lain yang dilakukan oleh Simbolon (2008) dan Carolus (2012) menyatakan bahwa BBLR bukan merupakan faktor risiko sepsis neonatorum. ${ }^{10,11}$ Bayi berat lahir rendah berisiko tinggi mengalami infeksi atau sepsis neonatorum kemungkinan karena pematangan organ tubuhnya yang belum sempurna (hati, paru, pencernaan, otak, daya pertahanan tubuh dll) yang menyebabkan bayi lebih mudah terkena infeksi. ${ }^{14}$ Kemungkinan lainnya adalah karena bayi berat lahir rendah sering mengalami kesulitan atau kurang mampu menghisap ASI yang berakibat terjadinya penurunan daya tahan tubuh dan memudahkan terjadinya infeksi. ${ }^{6}$

Pada penelitian ini dijumpai bahwa pemasangan infus merupakan faktor risiko yang bermakna terhadap kejadian sepsis neonatorum, namun demikian perlu diketahui bahwa infus diberikan kepada bayi setelah mengalami sepsis neonatorum atau sudah terjadi sepsis neonatorum terlebih dahulu baru kemudian diberi infus. Dengan demikian kemungkinannya adalah bayi yang sepsis neonatorum (sebagai kasus) cenderung diberi infus dibandingkan bayi yang tidak sepsis neonatorum (sebagai kontrol) dan kemungkinan bukan karena pemberian infus yang meningkatkan risiko terjadinya sepsis neonatorum pada bayi.

Dalam penelitian ini variabel lain yaitu jenis kelamin bayi, pekerjaan ibu, usia kehamilan, asfiksia, ibu tersangka keputihan, ibu tersangka infeksi saluran kencing, rujukan, pemasangan infus, penggunaan inkubator, penggunaan oksigen dan pemakaian CPAP tidak dijumpai meningkatkan risiko sepsis neonatorum.

Berkaitan dengan jenis kelamin bayi, pada hasil penelitian ini tidak sesuai dengan teori yang menyatakan bahwa bayi dengan jenis kelamin laki-laki lebih berisiko mengalami sepsis neonatorum lebih besar dari bayi perempuan karena aktivitas bayi laki-laki lebih tinggi daripada perempuan sehingga memerlukan oksigen lebih banyak dan apabila kandungan oksigen dalam tubuh berkurang menyebabkan bakteri anaerob mudah berkembang. ${ }^{21,24}$

Berkaitan dengan pekerjaan ibu hasil penelitian ini tidak sesuai dengan teori yang menyatakan bahwa ibu yang bekerja dengan menyita banyak waktu dan berpenghasilan minim lebih berisiko mengalami sepsis neonatorum. Sebanyak 25\% dari rumah tangga sangat tergantung pada pendapatan kaum perempuan. ${ }^{26}$ Selain untuk membantu membantu menopang sosial ekonomi keluarganya yang rendah, ibu yang bekerja tersebut juga mengelola rumah tangga seperti menyiapkan makanan, mengasuh dan merawat anak. ${ }^{27}$ Ibu hamil yang bekerja terlalu keras tetapi asupan makanannya kurang atau tidak adekuat akan cenderung melahirkan bayi dengan berat lahir rendah. Hasil penelitian ini sejalan dengan hasil penelitian Ambarwati (2011) yang menyatakan bahwa pekerjaan ibu hamil risiko tinggi sebagian besar terjadi pada pekerjaan yang tidak terampil karena pekerjaan ibu kebanyakan adalah buruh dengan penghasilan rendah. ${ }^{27}$

Berkaitan dengan usia kehamilan ibu hasil penelitian ini tidak sesuai dengan penelitian Roeslani di Divisi Perinatologi RSCM Jakarta 
2012 yang mendapatkan usia gestasi<37 minggu berpengaruh terhadap faktor risiko terjadinya sepsis neonatorum. ${ }^{9}$ Demikian juga pada penelitian Utomo (2012) di RS. Dr. Soetomo bahwa persalinan prematur berisiko lebih tinggi dibandingkan bayibayi yang lahir cukup bulan. ${ }^{14}$ Usia kehamilan adalah lama kehamilan dihitung dari hari pertama haid yang terakhir yaitu 280 hari atau 40 minggu. Usia kehamilan dibedakan atas kehamilan 36-40 minggu dari haid terakhir disebut cukup bulan atau matur, usia kehamilan 28-35 minggu disebut prematur dan usia kehamilan $>42$ minggu disebut serotinus. Bayi yang dilahirkan prematur memiliki sistem imun yang masih belum matang (relatively immune deficient) sehingga bisa menjadikan faktor predisposisi atau memudahkan terjadi infeksi. ${ }^{19}$

Berkaitan dengan asfiksia pada bayi, pada penelitian ini bukan merupakan faktor risiko sepsis neonatorum. Asfiksia adalah suatu keadaan gawat bayi berupa kegagalan bernafas secara spontan dan teratur segera setelah lahir dengan melihat indikator nilai apgar score yang rendah yang dapat mengakibatkan hipoksia, hiperkarbia dan asidemia yang selanjutnya akan meningkatkan pemakaian sumber energi dan mengganggu sirkulasi bayi. ${ }^{9}$ Bayi dengan apgar score rendah pada menit pertama meningkatkan kebutuhan prosedur ventilasi mekanik dan pemasangan kateter umbilikal sehingga meningkatkan terjadi risiko sepsis neonatorum pada bayi-bayi baru lahir. ${ }^{20}$ Di Nepal, asfiksia menjadi penyebab utama kematian neonatal dini $33,0 \% .^{15}$

Berkaitan dengan ibu hamil yang tersangka keputihan pada penelitian ini dijumpai bukan merupakan faktor risiko terjadinya sepsis neonatorum. Keputihan pada ibu hamil adalah normal dan tidak menyebabkan bahaya. ${ }^{9}$ Keputihan pada ibu hamil bila tidak berbau dan tidak membuat gatal akan sampai pada masa akhir kehamilan keputihan dan semakin meningkat karena infeksi jamur semakin berat terjadi. ${ }^{22}$

Berkaitan dengan ibu hamil yang tersangka infeksi saluran kencing pada penelitian ini dijumpai tidak sesuai dengan teori yang menyatakan faktor risiko infeksi grup B streptokokus (GBS) pada ibu yang dapat terjadi pada vagina ibu atau urin selama kehamilan yang menyebabkan ibu demam intrapartum bahkan KPD. ${ }^{25}$ Infeksi pada ibu pada saat melahirkan, terutama infeksi saluran genital merupakan jalur penting transmisi maternal dan berperan penting dalam timbulnya infeksi pada neonatal. ${ }^{22}$

Berkaitan dengan sistem rujukan, hasil penelitian ini tidak sesuai dengan teori yaitu bayi yang dirujuk cenderung berisiko dikarenakan selain bayi masih kecil dan kondisi cepat memburuk di lapangan, sistem transport neonatal yang belum berkembang dengan baik di Indonesia dan kendala sosial ekonomi karena perawatan bayi kecil mahal dan cukup lama. ${ }^{23}$ Sistem rujukan merupakan tatanan berbagai komponen dalam jaringan pelayanan kesehatan untuk berinteraksi timbal balik antara tenaga kesehatan di pelayanan dengan klasifikasi rendah ke pelayanan kesehatan tingkatan yang lebih tinggi (bidan desa, bidan dan dokter puskesmas dengan dokter spesialis di RSJ untuk mencapai rasionalisasi penggunaan sumber daya kesehatan dalam penyelamatan pasien yang berisiko tinggi atau gawat darurat. ${ }^{24}$

Berkaitan dengan tindakan invasif pada penelitian ini dijumpai tidak sesuai dengan teori yang menyatakan tindakan invasif seperti pemasangan infus dapat menimbulkan komplikasi/kejadian yang tidak diinginkan..$^{12,17}$

Hasil penelitian ini tidak bisa digeneralisir ke populasi karena kasus dan kontrol hanya diambil dari pasien yang berkunjung ke RSUP Sanglah. Selain itu karakteristik lingkungan Kota Denpasar/ Bali tidak sama dengan daerah lainnya. Kelemahan penelitian lainnya adalah karena informasi tentang faktor risiko diperoleh dari rekam medik dimana banyak rekam medik tidak lengkap dan banyak rekam medik tidak dijumpai.

\section{SIMPULAN}

Satu-satunya faktor risiko yang secara bermakna meningkatkan kejadian sepsis neonatorum di ruang perinatologi RSUP Sanglah Denpasar adalah bayi berat lahir rendah sedangkan variabel lainnya tidak dijumpai sebagai faktor risiko.

\section{UCAPAN TERIMA KASIH}

Terimakasih disampaikan kepada Direktur RSUP Sanglah, staf ruang perinatologi dan staf ruang rekam medik RSUP Sanglah Denpasar dan semua pihak yang telah membantu pelaksanaan penelitian ini.

\section{DAFTAR PUSTAKA}

1. WHO. Millenium Development Goals: Progress toward the Health-Related Millenium Development Goals; 2010.

2. WHO. Infant Mortality; 2013.

3. Depkes RI. Survei Demografi dan Kesehatan Indonesia (SDKI) tahun 2012. Jakarta: Depkes RI; 2013.

4. Dinas Kesehatan Propinsi Bali. Profil Kesehatan Propinsi Bali tahun 2013. Denpasar: Dinas Kesehatan Provinsi Bali; 2014.

5. Departemen Kesehatan RI. Panduan Konseling Bagi Petugas Klinik dan Sanitasi di Puskesmas. Jakarta: Depkes RI; 2000.

6. Fikawati, S. Kajian Implementasi dan Kebijakan Air Susu Ibu Eksekutif dan Inisiasi Menyusui Dini di Indonesia. 2010 
7. Junara, P. Insiden dan Faktor-faktor yang Berhubungan dengan Sepsis neonatorum Neonatus di RSUP Sanglah Denpasar. Saripediatri; 2012.

8. Leal, A.Y., etc. Risk Factor and Prognosis for Neonatal Sepsis neonatorum in Shourten Mexico; 2012.

9. Roeslani, D.R. dkk. Penelitian Awal: Faktor Risiko pada Sepsis neonatorum Neonatorum Awitan Dini. Saripediatri; 2013.

10. Sastroasmoro, S. dkk. Dasar-dasar Metodologi Penelitian Klinis. Jakarta: CV. Sagung Seto; 2011.

11. Simbolon, D. Risk Faktor of Sepsis neonatorum Neonatorum at District Hospital in Curup Rejang Lebong Indonesia. Sumatera Utara; 2008.

12. Carolus, W. Hubungan Apgar Score dan Berat Badan Lahir dengan Sepsis neonatorum Neonatorum. Samratulangi; 2012.

13. Setiasih, Y., dkk. Peripherally Inserted Central Catheter dan Pemberian Terapi Intravena pada Neonatus. Bandung; 2012.

14. Mark, H. B., Robert, B. From The Merck Manual of Medical Information Home Edition. New Jork; 1997.

15. Utomo, T.M. Risk Factor of Neonatal Sepsis neonatorum: A Premilinary Study in Dr. Soetomo Hospital. Indonesia; 2010.

16. Manuaba, L.B. Ilmu Kebidanan, Penyakit Kandungan dan keluarga Berencana untuk Pendidikan Bidan. Jakarta: EGC; 2001.

17. Cloherty, J.P. Manual of Neonatal Care. USA; 2010

18. Baria, R.M., Lorca, P., \& Munoz, S. RRandomized controlled trial of vascular acces in newborn in neonatal intensive care unit. JOGNN Clinical Research; 2007.
19. Sulistijono Eko., dkk. Faktor Risiko Sepsis neonatorum Awitan Dini pada Neonatus; 2013.

20. Wong NA, Hunt LP, and Marlow N. Risk Factors for Developing Neonatal Septicemia at Malaysian Hospital. Journal of Pediatrics; 1997;43(1):54-58.

21. Aminullah A. Sepsis neonatorum pada bayi baru lahir. Dalam: Kosim MS. Yunnato A. Dewi R. Sarosa GI, Usman A. Buku Ajar neonatologi. Jakarta. Badan Penerbit IDAI; 2014; 170-185.

22. Wilar R., dkk. Faktor Risiko Sepsis neonatorum Awitan Dini; 2010 .

23. Siswanto, J.E., dkk. Angka Kematian Sepsis neonatorum Neonatal Pada Bayi Risiko Tinggi. Saripediatri; 2007; 8(3):48-56

24. Rochjati, P. Pelayanan Kebidanan Di Indonesia. In: Saifuddin A.B, Rachimhadhi T, wiknjosastro G.H, editors. Ilmu kebidanan ed.4, cet.3. Jakarta: PT. Bina Pustaka; 2010.

25. McGuire. W, Clerihew. L, Fowlie. PW. Infection in the preterm infant. BMJ; 2004; 329:1277-8.

26. Tinker, A. and Koblinsky, M. Making Motherhood Safe. Washington DC: World Bank; 1993.

27. Ambarwati, M.R, dkk. Gambaran Faktor Penyebab Ibu Hamil Risiko Tinggi Tahun 2005-2010 di Polindes Sambikerep Kecamatan Rejoso Kabupaten Nganjuk; 2011.

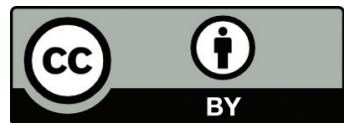

This work is licensed under a Creative Commons Attribution 